TAO, Vol. 14, No. 4, 421-430, December 2003

\title{
Relocation of the 1998 Rueyli, Taiwan, Earthquake Sequence Using Three-dimensions Velocity Structure with Stations Corrections
}

\author{
Yih-Min $\mathrm{Wu}^{1}$, Chien-Hsin $\mathrm{Chang}^{1}$, Nai-Chi Hsiao ${ }^{1}$, and Francis T. Wu ${ }^{2}$ \\ (Manuscript received 28 March 2003, in final form 30 September 2003)
}

\begin{abstract}
To improve location identification, we employed layered model joint hypocenters determination (JHD) and double-difference earthquake location algorithm (hypoDD), three-dimensions velocity structure location (3DLOC), and three-dimensions velocity structure with stations corrections location (3DCOR) for the Rueyli, Taiwan, earthquake sequence. We found that the 3DCOR can greatly improve the location identification precision of the Rueyli earthquake sequence. The Rueyli mainshock was relocated to $23.510^{\circ} \mathrm{N}, 120.660^{\circ} \mathrm{E}$ at the depth of $5.6 \mathrm{~km}$. The focal depth is significantly deeper than the original CWBSN value of $2.8 \mathrm{~km}$. Using this new location, a first-motion fault-plane solution shows that this earthquake is a thrust event with strike $\mathrm{N}^{\circ} 3^{\circ} \mathrm{E}$, dip $42^{\circ} \mathrm{E}$, and rake $121^{\circ}$. Based on the hypocentral distribution pattern ascertained after relocation and focal mechanism, the Rueyli earthquake was probably caused by faulting in the Tachienshan fault.
\end{abstract}

(Key words: Earthquake location, Three-dimensions velocity structure earthquake location, JHD, HypoDD)

\section{INTRODUCTION}

The success of most seismological studies relies on the accuracy of earthquake locations. The accuracy of the hypocenter locations is controlled by several factors, including the network geometry, available phases, arrival time reading accuracy, and knowledge of the crustal structure.

Taiwan is located on the western Circum-Pacific seismic belt. The Philippine Sea plate subducts northward under the Eurasia plate along the Ryukyu trench. The Eurasia plate sub-

\footnotetext{
${ }^{1}$ Seismological Observation Center of the Central Weather Bureau, Taiwan

${ }^{2}$ Department of Geological Science State University of New York at Binghamton, NY 13902, USA

${ }^{*}$ Corresponding author address: Dr. Yih-Min Wu, Seismological Observation Center of the Central

Weather Bureau, 64 Kung-Yuan Road, Taipei 100, Taiwan, ROC; E-mail: ym.wu@ socmail.cwb.gov.tw
} 
ducts eastward under the Philippine Sea plate off the southern tip of Taiwan. The interactions between these two plates have resulted in a very complicated crustal structure in the Taiwan region. This complex and not well-determined velocity structure can cause large uncertainties in earthquake locations.

Using a layered velocity model to locate earthquakes is not satisfactory, because such a model can not describe a three-dimensional velocity structure and thus can introduce significant errors in the calculated travel times. In the past, researchers have developed various techniques to reduce the effects of a 3-D velocity structure on identifying earthquake locations. The JHD approach is a method of estimating and removing station corrections from source regions (e.g., Douglas 1967; Deway 1971; Frohlich 1979; Pujol 1988). In seismic tomography, hypocenters and velocity structure are determined jointly (e.g., Aki and Lee 1976; Crosson 1976; Ellsworth 1977; Roecker 1981; Thurber 1983). Recently, Waldhauser and Ellsworth (2000) proposed a hypoDD method to minimize errors due to unmodeled velocity structure without the use of station corrections. Residuals between observed and theoretical travel time differences are minimized for pairs between closely spaced earthquakes at each station and linking together all observed event-station pairs.

The above methods can improve the precision for earthquake relocation, but most of them are based on a layered velocity model, which is still inadequate for the Earth. The 3DLOC may be a good way to improve location accuracy. But, the seismic tomography approach for jointly inverting for hypocenters and three-dimensional velocity structure, yield an average structure. For earthquake sequence (a series closely spaced earthquakes) relocation, we need a finer local structure. Thus, in this study we wrote a computer program (called 3DCOR) to improve the accuracy of earthquake sequence relocation.

On 17 July 1998, a damaging earthquake $\left(M_{L}=6.2\right)$ took place near the town of Reuyli in southwestern Taiwan, approximately $25 \mathrm{~km}$ northeast of Chiayi city. The epicenter of the mainshock was located at $23.51^{\circ} \mathrm{N}$ and $120.66^{\circ} \mathrm{E}$ with a focal depth of $6.0 \mathrm{~km}$ (Chang et al. 1998; Wu et al. 1998). The mainshock was felt throughout Taiwan. It caused landslides, rockfalls and damage to buildings in the epicentral area. The rockfalls killed five people and injured several others. There were several hundreds of aftershocks in the following days. The Rueyli earthquake sequence took place in an area well monitored by of the CWB Seismic Network (CWBSN) as shown in Fig. 1. Thus, it offers a good opportunity to study the earthquake sequence relocation problem.

In this study, we relocated the Rueyli earthquake sequence (Chang et al. 1998; Wu et al. 1998; Chen et al. 1999; Chen et al. 2003a, b), using the following computer programs: JHD, hypoDD (Waldhauser 2001), 3DLOC (Thurber and Eberhart-Phillips 1999), and 3DCOR. The 3DCOR program is modified from the 3DLOC program with the station correction terms added in the location process.

\section{DATA AND ANALYSIS}

A total of 384 events (from 17 July to 31 July 1998) were recorded by CWBSN (Fig. 2). The CWBSN consists of a central recording system with 73 telemetered stations (Fig. 1). 


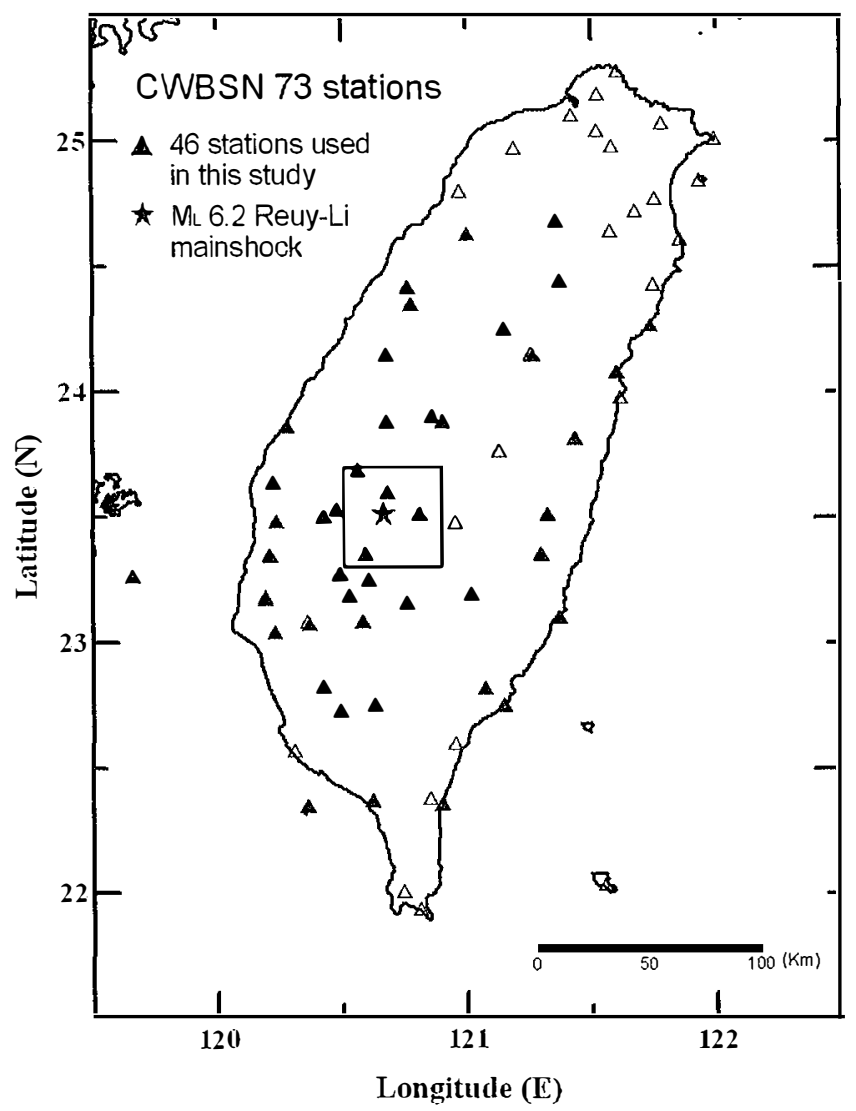

Fig. 1. Stations distribution of the Central Weather Bureau Seismic Network (CWBSN; triangles), and the Rueyli mainshock epicenter (star). The solid triangles show 46 stations used in this study. The rectangle shows the study area.

Each station is equipped with a 3-component, short-period S13 seismometer. Signals are digitized at 100 samples per second at 12-bit resolution in the field and are transmitted via dedicated telephone lines to the recording center in Taipei.

The selection of earthquakes was based on the following criteria: (1) earthquakes were located in the region from latitude $23.3^{\circ} \mathrm{N}$ to $23.7^{\circ} \mathrm{N}$ and longitude $120.5^{\circ} \mathrm{E}$ to $120.9^{\circ} \mathrm{E}$ (Fig. 1); (2) $\mathrm{P}$ or $\mathrm{S}$ arrivals were clearly recorded by at least 6 stations with epicentral distance less than $150 \mathrm{~km}$ for the events. 46 CWBSN stations were used in this study (Fig. 1).

Several studies (Roecker et al. 1987; Rau and Wu 1995; Ma et al. 1996; Chen and Shin 1998) have investigated the three-dimensional velocity structures in Taiwan. Considering the consistency in ray tracing method developed by Thurber (1993), we used the 3-D velocity structure determined by Chen and Shin (1998) in this study. The layered model determined in their study was also employed in the JHD and hypoDD relocation. The station corrections were determined from the averaged travel time residuals with weighting after three-dimen- 

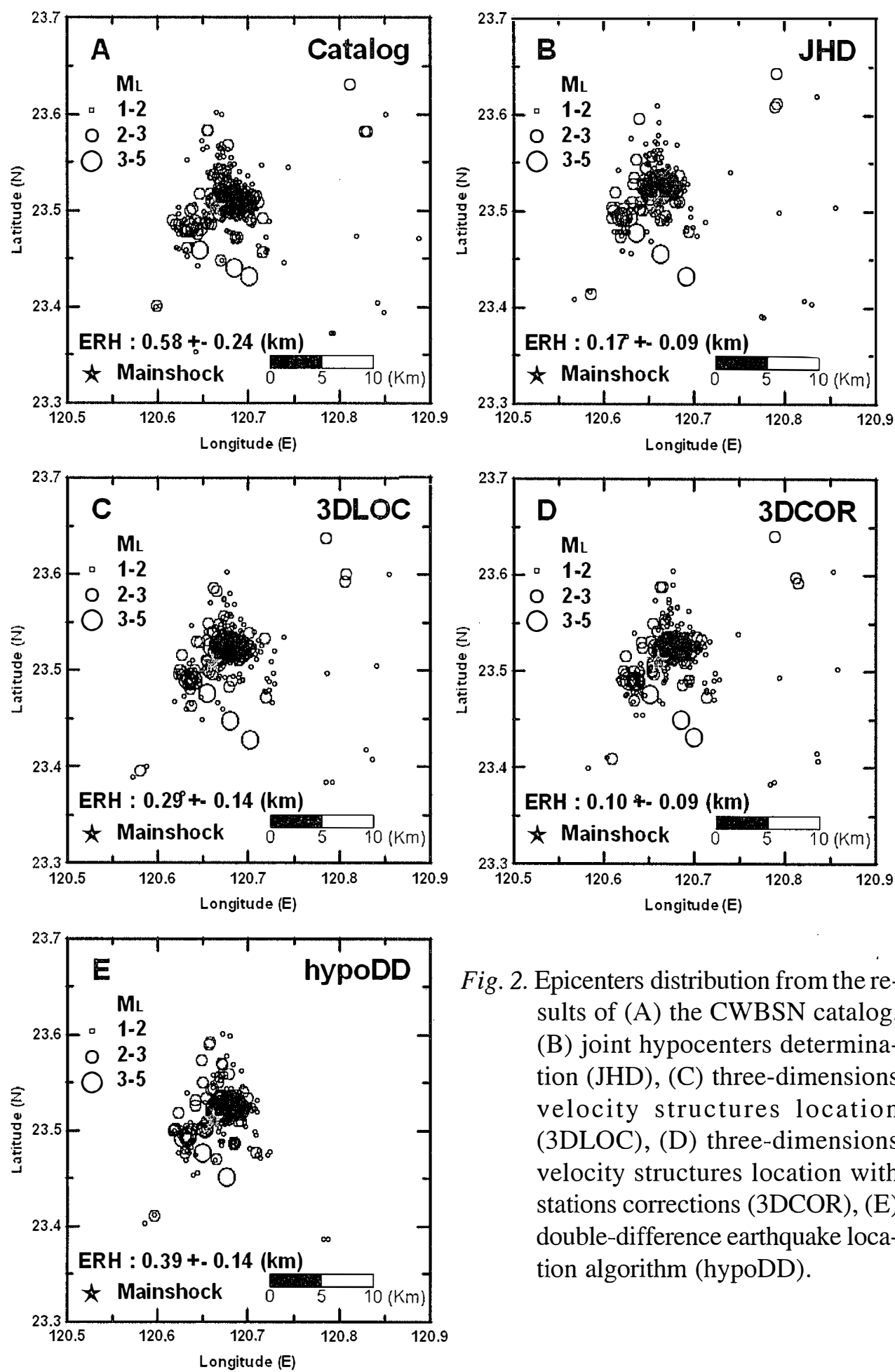

Fig. 2. Epicenters distribution from the results of (A) the CWBSN catalog, (B) joint hypocenters determination (JHD), (C) three-dimensions velocity structures location (3DLOC), (D) three-dimensions velocity structures location with stations corrections (3DCOR), (E) double-difference earthquake location algorithm (hypoDD). 
Table 1 The statistical error estimates of the averaged ER H, ERZ, and RMS from the CWBSN catalog and the results of the JHD, hypoDD, 3DLOC, and $3 \mathrm{DCOR}$ relocations in this study for the Rueyli earthquake sequence.

\begin{tabular}{|c|c|c|c|c|c|}
\hline & Catalog & JHD & hypoDD & 3DLOC & 3DCOR \\
\hline RMS (sec) & $0.27 \pm 0.07$ & $0.12 \pm 0.04$ & $0.14 \pm 0.03$ & $0.19 \pm 0.03$ & $0.08 \pm 0.03$ \\
\hline ERH $(\mathrm{km})$ & $0.58 \pm 0.24$ & $0.17 \pm 0.09$ & $0.39 \pm 0.14$ & $0.29 \pm 0.14$ & $0.10 \pm 0.09$ \\
\hline ERZ $(\mathrm{km})$ & $0.83 \pm 0.31$ & $0.31 \pm 0.17$ & $0.40 \pm 0.19$ & $0.54 \pm 0.27$ & $0.17 \pm 0.17$ \\
\hline
\end{tabular}

sions location of all events. Generally, we can obtain stable station correction values after three iterations.

\section{RESULTS}

We used the JHD, hypoDD, 3DLOC, and 3DCOR computer programs to relocate the events. Only 371 events were relocated by the hypoDD program, because it removed some poorly linked events. On the basis of three statistical error estimates, i.e., the root-mean-square (RMS) of travel time residuals, the error in depth (ERZ) and the error in epicenter (ERH; Flinn 1965) calculated for the CWBSN catalog, we found the JHD, hypoDD, 3DLOC, and 3DCOR programs provided improved results as shown in Table 1. The 3DCOR method gave the best results in the statistical error estimates because of station corrections were applied. The JHD and hypoDD results also performed well in the RMS term. Figures 2, 3 show epicentral and hypocentral distributions of the CWBSN catalog and the results from the JHD, 3DLOC, 3DCOR and hypoDD relocations, respectively. The results from JHD, 3DCOR, and hypoDD relocations give a similar hypocentral distribution pattern (Fig. 3). Most aftershocks occurred close to mainshock and formed a dipping-to-the east seismic zone. The results from these three methods also perform better in statistical error estimates (i.e. RMS, ERH, and ERZ). We suggest that this pattern may be close to "true" hypocentral distribution. Figure 4 indicates the location difference between the CWBSN catalog and the results of the 3DCOR relocations. After the 3DCOR relocations, the focal depth of the most events concentrated near the mainshock hypocenter. Some events in the CWBSN catalog were located to very shallow depths. We suggest that this was caused by using a layered velocity model in the location.

\section{DISCUSSIONS AND CONCLUSIONS}

We relocated the Rueyli earthquake sequence by using the JHD, hypoDD, 3DLOC, and 3DCOR computer programs. According to the three statistical error estimates (Table 1) and 

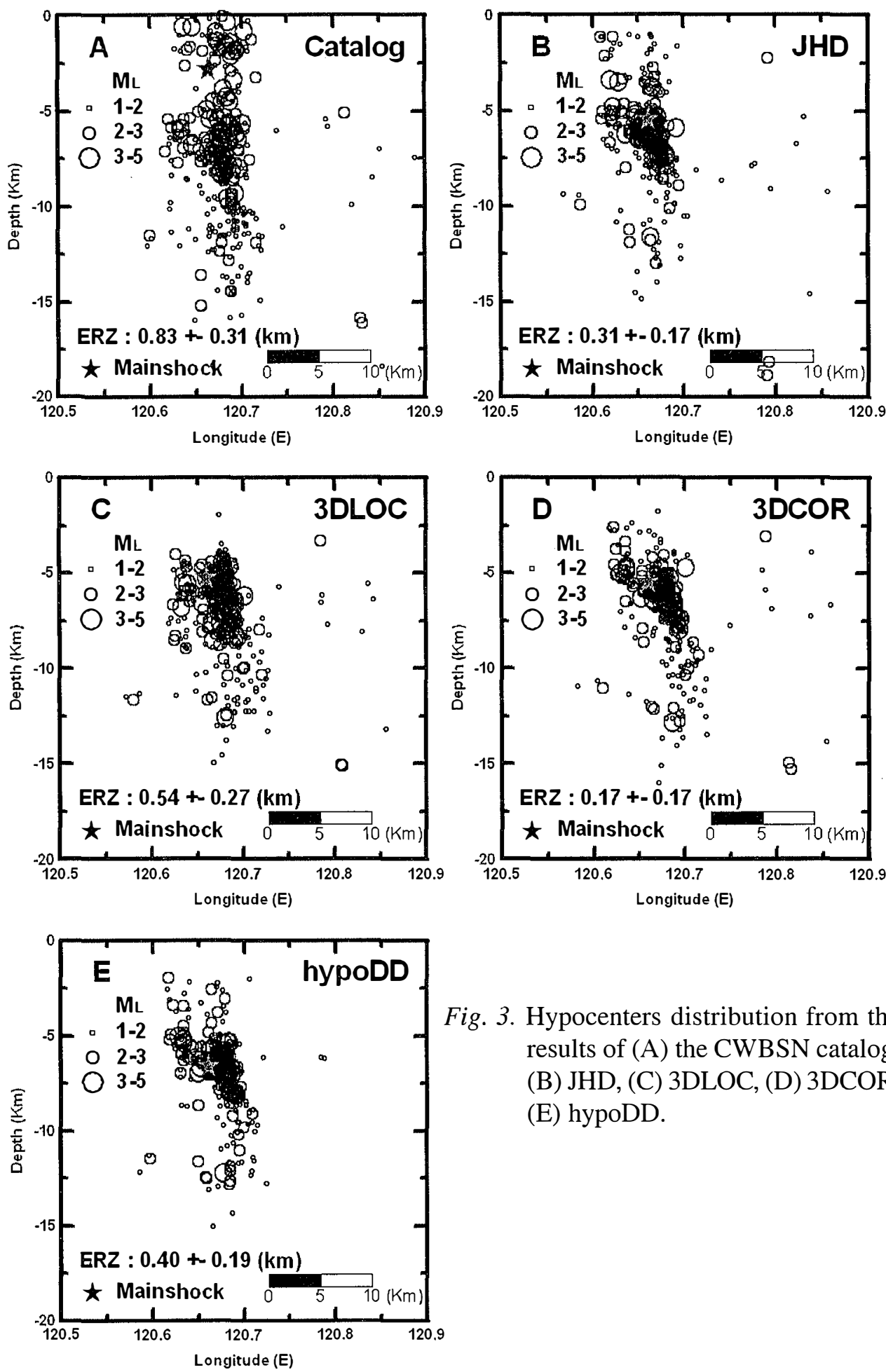

Fig. 3. Hypocenters distribution from the results of (A) the CWBSN catalog, (B) JHD, (C) 3DLOC, (D) 3DCOR, (E) hypoDD. 

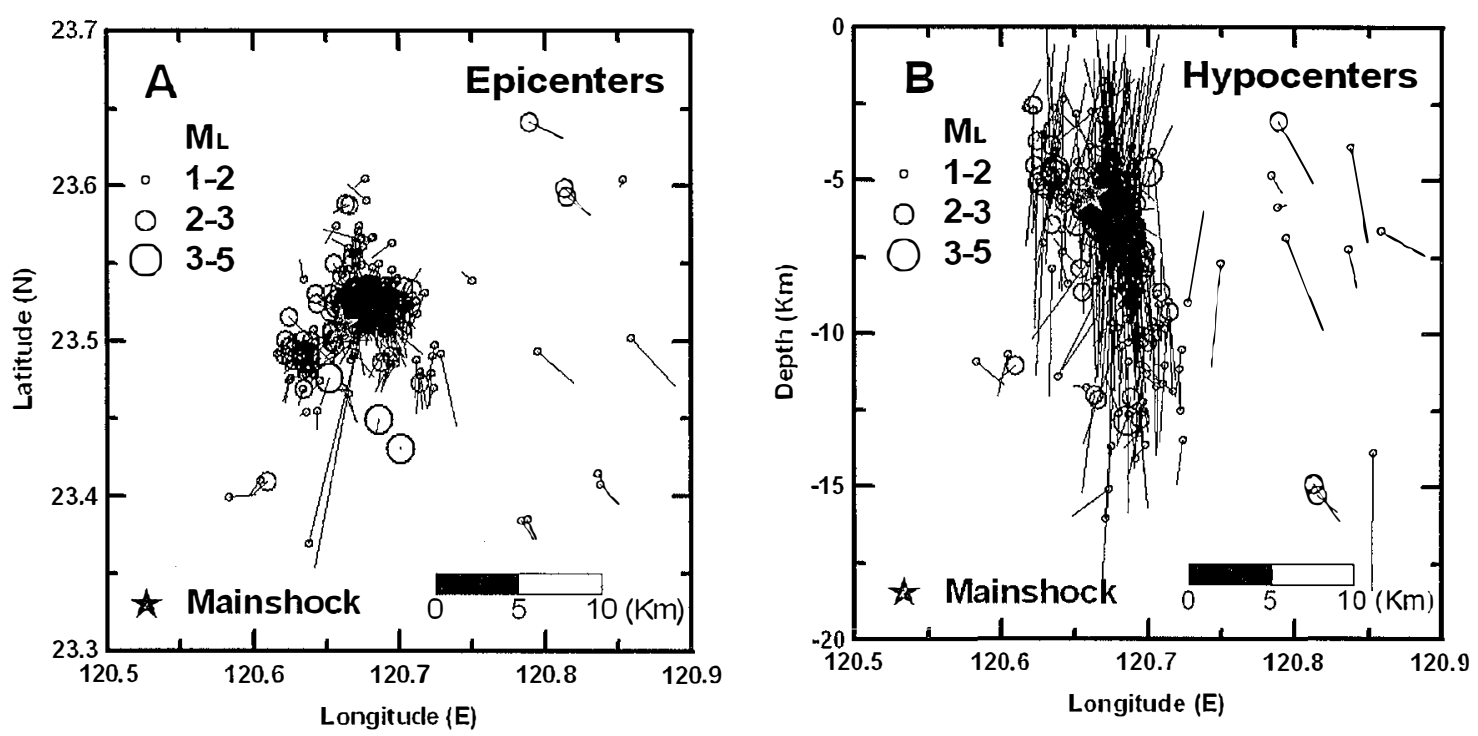

Fig. 4. Location difference between the CWBSN catalog and the results of the 3DCOR. Open circles indicate the location of the 3DCOR, and the other end of the connected line shows the CWBSN catalog location of the same event.

(A) CWBSN Catalog

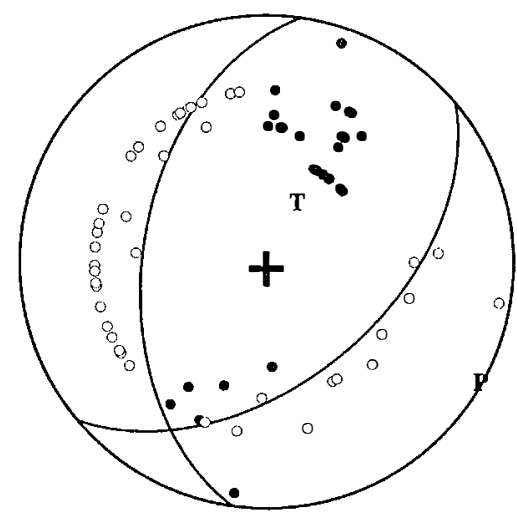

Strike : $50^{\circ}$

dip : $50^{\circ}$

rake $: 120^{\circ}$
(B) 3DCOR

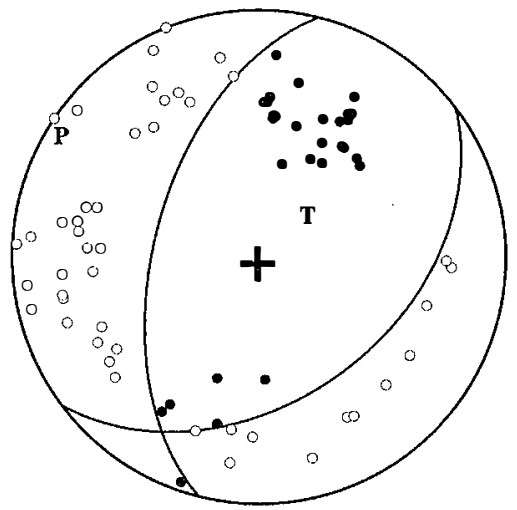

Strike : $53^{\circ}$

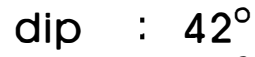

rake : $121^{\circ}$

Fig. 5. Two first-motion fault-plane solutions were determined by using (A) the CWBSN catalog and (B) the 3DCOR source locations. The first P polarities were from the CWBSN and the Taiwan Strong Motion Instrumentation Program (TSMIP) stations. 
Table 2. Source parameters determined by the CWBSN catalog and the 3DCOR relocation in this study.

\begin{tabular}{|c|c|c|c|c|c|c|}
\hline & Lat. (N) & Long. (E) & Depth (km) & RMS (sec) & ERH (km) & ERZ (km) \\
\hline Catalog & $23.503^{\circ}$ & $120.663^{\circ}$ & 2.8 & 0.34 & 0.50 & 1.00 \\
\hline 3DCOR & $23.510^{\circ}$ & $120.660^{\circ}$ & 5.6 & 0.04 & 0.02 & 0.04 \\
\hline
\end{tabular}

3DCOR Relocation 384 events

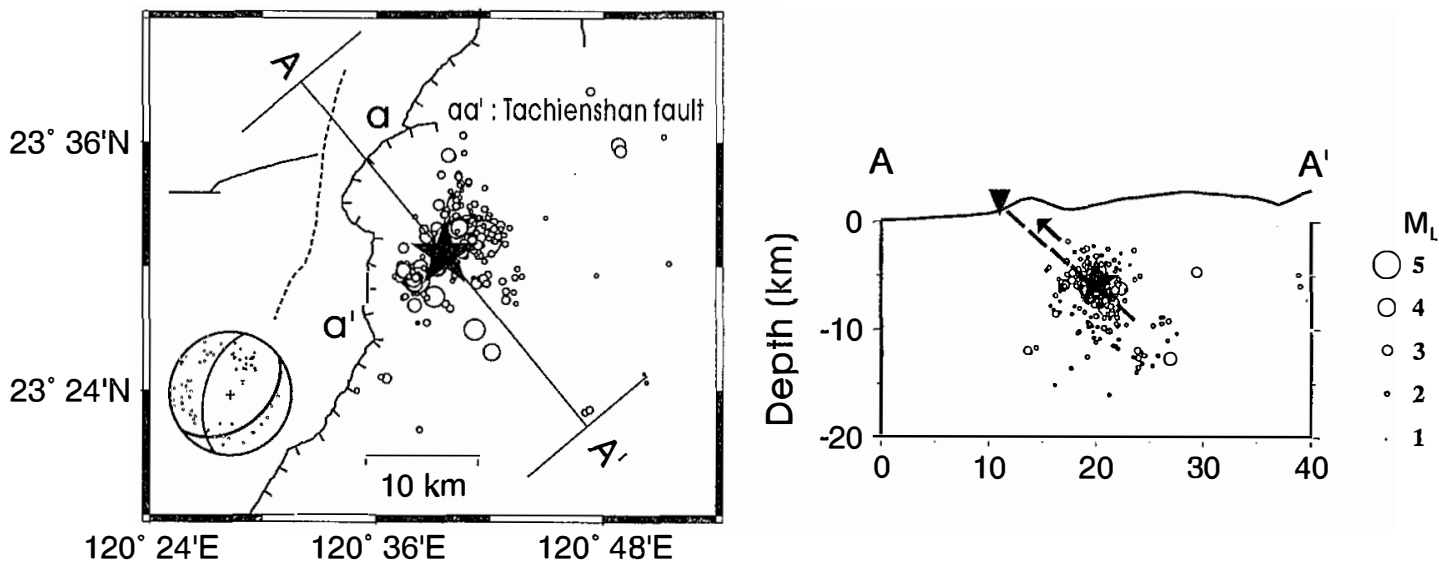

Fig. 6. Epicenters distributions and a profile of the hypocenters along the dip direction of the Rueyli earthquake sequence of the 3DCOR relocation.

hypocentral distribution pattern (Figs. 2, 3), we conclude that the 3DCOR program is a useful method to improve the earthquake sequence relocation.

After the 3DCOR relocation, the mainshock was located to $23.510^{\circ} \mathrm{N}, 120.660^{\circ} \mathrm{E}$ at the depth of $5.6 \mathrm{~km}$. The focal depth is deeper than that reported in Chen et al. (2003a). Compared with the CWBSN catalog, the focal depth changed from $2.8 \mathrm{~km}$ to $5.6 \mathrm{~km}$, the ERH, ERZ, and RMS estimates were greatly improved by about one order of magnitude (Table 2). Using the 3DCOR location and the CWBSN catalog, we reexamined the first-motion fault-plane solution (Fig. 5). The first P polarities were collected from the CWBSN and the Taiwan Strong Motion Instrumentation Program (TSMIP) stations. Obviously, the 3DCOR location greatly improved the focal mechanism determination. Figure 5B includes several first $\mathrm{P}$ motions near the nodal planes, which offer good constraints in the fault-plane solution. All the first P-motion polarities agree to this fault-plane solution, suggesting the focal mechanism established in this study is consistent with the relocated hypocenter by the 3DCOR program.

The focal mechanism of the Rueyli mainshock (Fig. 4B) indicates a thrust event with strike $\mathrm{N} 53^{\circ} \mathrm{E}, \operatorname{dip} 42^{\circ} \mathrm{E}$ and rake $121^{\circ}$. The strike is consistent with the north segment of the Tachienshan fault. Figure 6 shows the epicentral distributions and a profile of the hypocenters along the $\mathrm{N} 143^{\circ} \mathrm{E}$ from the $3 \mathrm{DCOR}$ relocations. The distribution of relocated aftershocks in 
the profile is dipped about $40^{\circ}$ to southeast. This agrees to one of the nodal planes determined in this study. We suggest that this plane (Strike $\mathrm{N} 53^{\circ} \mathrm{E}$ and $\operatorname{dip} 42^{\circ} \mathrm{E}$ ) is the fault plane of the Rueyli earthquake. In the profile we plotted a line with a dip angle of $42^{\circ} \mathrm{E}$ through the mainshock. This line is projected near the Tachienshan fault. Thus, we suggest that the Rueyli earthquake was probably caused by faulting in the Tachienshan fault. This result is similar to Chen et al. (1999), which suggested that the aftershock activity be associated with Tachienshan and Shihkuping faults.

Acknowledgments The authors are deeply grateful to Prof. Willie Lee for improving this manuscript. We thank Profs. Ta-liang Teng, Chau-Huei Chen, Kou-Cheng Chen and two anonymous reviewers for their valuable comments. This work was supported by the Central Weather Bureau and the National Science Council of the Republic of China under Grant No. NSC912116-M-052-001 and NSC92-2119-M-052-003.

\section{REFERENCES}

Aki, K., and W. H. K. Lee, 1976: Determination of three-dimensional velocity anomalies under a seismic array using first $\mathrm{P}$ arrival times from local earthquakes, 1 , a homogeneous initial model. J. Geophys. Res., 81, 4381-4339.

Chang, C. H., T. C. Shin, and C. Y. Wang, 1998: Rueyli earthquake in 1998, Proceedings of the $7^{\text {th }}$ Taiwan Symposium on Geophysics, 1-12. (in Chinese)

Chen, C. H., W. H. Wang, and T. L. Teng, 2003a: Tectonics implication of 1998, Ruey-Li, Taiwan earthquake sequence. TAO, 14, 27-40.

Chen, C. H., W. H. Wang, and T. L. Teng, 2003b: A possible causal relationship between the 1998 Ruey-Li sequence and the 1999 Chi-Chi Earthquake in Taiwan. Bull. Seism. Soc. Am., 93, 1542-1558.

Chen, K. C., B. S. Huang, K. L. Wen, H. C. Chiu, Y. T. Yeh, S. N. Cheng, H. Y. Pen, T. M. Chang, T. C. Shin, R. C. Shih, and C. R. Lin, 1999: A study of aftershocks of the 17 July 1998 Reuyli Chiayi Earthquake, TAO, 10, 605-618.

Chen, Y. L., and T. C. Shin, 1998; Study on the earthquake location of 3-D velocity structure in Taiwan area. Meteor. Bull., 42, 135-169.

Crosson, R. S., 1976: Crustal structure modeling of earthquake data, 1, simultaneous least squares estimation of hypocenter and velocity parameter. J. Geophys. Res., 81, 30363046.

Dewey, J. W., 1971: Seismicity studies with the method of joint hypocenter determination. $\mathrm{Ph}$. D. Thesis, University of Calfornia at Berkeley, 166pp.

Douglas, A., 1967: Joint epicenter determination. Nature, 215, 47-48.

Ellsworth, W. L., 1977: Three-dimensional structure of the crust and mantle beneath the island of Hawaii, Ph. D. thesis, Mass. Inst. Of Technol., Cambridge, 327 pp.

Flinn, E. A., 1965: Confidence regions and error determinations for seismic event location. Rev. of Geophy., 3, 157-185.

Frohlich, C., 1979: An efficient method for joint hypocenter determination for large groups of 
earthquakes. Comp. Geosci., 5, 387-389.

Ma, K. F., J. H. Wang, and D. Zhao, 1996: Three-dimensional seismic velocity structure of the crust and uppermost mantle beneath Taiwan. J. Phys. Earth, 44, 85-105.

Pujol, J., 1988: Comments on the joint determination of hypocenters and station corrections. Bull. Seism. Soc. Am., 78, 1179-1189.

Rau, R. J., and F. T. Wu, 1995: Tomographic imaging of lithospheric structures under Taiwan. Earth Planet. Sci. Lett., 133, 517-532.

Roecker, S. W., 1981: Seismicity and tectonics of the Pamir-Hindu Kush region of central Asia, Ph. D. thesis, Mass. Inst. Of Technol., Cambridge, 294 pp.

Roecker, S. W., Y. H. Yeh, and Y. B. Tsai, 1987: Three-dimensional P and S wave velocity structure beneath Taiwan: deep structure beneath an arc-continent collision. J. Geophys. Res., 92, 10547-10570.

Thurber, C. H., 1983: Earthquake locations and three-dimensional crustal structure in the Coyote Lake area, central California. J. Geophys. Res., 88, 8226-8236.

Thurber, C. H., 1993: Local earthquake tomography: velocities and Vp/Vs- theory, in Seismic Tomography: Theory and practice edited by H. M. Iyer and K. Hirahara published by Chapman \& Hall, London, U. K.

Thurber, C., and D. Eberhart-Phillips, 1999: Local earthquake tomography with flexible gridding. Comp. Geosci., 25, 809-818.

Waldhauser, F, 2001: A program to compute double-difference hypocenter locations (hypoDD version 1.0, 3/2001), U.S. Geol. Surv. Open-File Rept. 01-113.

Waldhauser, F., and W. L. Ellsworth, 2000: A double-difference earthquake location algorithm: method and application to the northern Hayward fault, California. Bull. Seism. Soc. Am., 90, 1353-1368.

Wu, Y. M., C. H. Chang, and T. C. Shin, 1998: A preliminary study of 1998 Rueyli earthquake. Meteor. Bull., 42, 343-355. (in Chinese) 